\title{
Factors affecting microclimatic conditions in urban environment
}

\author{
Irina Giyasova ${ }^{1, *}$ \\ ${ }^{1}$ Moscow State University of Civil Engineering, Yaroslavskoe shosse, 26, Moscow, 129337, Russia
}

\begin{abstract}
Urbanization leads to dramatic changes in urban microclimate, and becomes a serious problem in terms of ensuring comfortable and healthy living of city dwellers. The main factors affecting the microclimate of urban environment are not only the geographical features of cities, but also the density of buildings, the environmental concerns, the thermal response of buildings, the influence of plants and water bodies. The problem of the urban microclimate optimization is multifaceted since various factors affect changes in the urban environment. Thus an integrated multilevel systematic approach to studying the problems of the formation of the urban microclimate is required. Integrating the accumulated knowledge and practices in the research domain with design work is important.
\end{abstract}

\section{Introduction}

Today, cities are characterized by an increase in density of high-rise buildings, which creates new opportunities for the socio-economic development of society. More and more complex urban systems are emerging, which influence the urban microclimate through their development and growth. In this case, dynamic environmental and meteorological factors also appear following the changes in the structure of the urban system.

Modern research shows that the problems of geography, air temperature and urban development are closely connected. Scientists address a range of issues including those related to the impact of building density on the distribution of air flows; they consider the issue of dispersion of pollutants in high-density urban models with different building densities and variations in heights, issues of thermal response of buildings and the formation of an urban heat island, assessment of the influence of plants, natural and artificial reservoirs on the microclimate in an urban environment.

Urban development changes the natural relief: it increases the roughness of the underlying surface (for example, it forms basin conditions against the background of a flat relief), includes many vertical surfaces, and creates rough terrain. Such impacts as urban heat and dry islands, changes in precipitation rate, frequency and intensity are formed [1]. In this regard, the study of the impact of various factors on the formation of microclimatic conditions in the urban environment is becoming increasingly important. This is a wide research field with many different combinations of factors influencing the microclimate of the city. The

\footnotetext{
* Corresponding author: timrus64@mail.ru
} 
most relevant is the study of energy modeling methods that take into account the local microclimate and the influence of neighboring buildings.

In the more complex geometry of the urban environment, areas with shading effects are formed, thus reducing the time of insolation during the daytime. In this case, the sky view factor decreases, which limits the radiation cooling of the sky. In addition, solar and infrared interflections are increasing with the surfaces of neighboring buildings [2]. The surrounding buildings significantly alter the airflow and redirect it. In large cities, the air temperature throughout the year is several degrees higher than in the adjacent territories. Urban heat islands are forming, which are known to be characterized by higher air temperatures compared to the periphery. The center of the heat islands is shifted from the city center towards the direction of the prevailing winds.

Urban heat islands and heat waves have a serious impact on the quality of life of people: on the one hand, these phenomena, changing the environment, affect health; on the other hand, they pose serious problems for construction design when solving the issues of increased energy demand for space cooling and thus worsening the thermal environment indoors [3].

\section{Materials and Methods}

In urban environment, the climate changes due to the configuration of the city and the thermal properties of the Earth's surface. Thermal conditions of cities are different within the city itself, and the study of the diversification of the intracity microclimate is of extreme importance for identifying the most critical conditions for the well-being of citizens and assessing the real needs of buildings for energy [4].

The model shown in Fig. 1 demonstrates an integrated multi-level and systematic approach to the study of the formation of the urban microclimate. The problem of the urban microclimate optimization can be solved at many levels, since various factors affect it at different levels (the meso level, the district level, the microdistrict level, the building level). The multiscale urban climate modeling system proposed in [5] combines mesoscale, local, micro-scale and large-scale modeling of buildings. The model allows the building energy model to take into account the local climate.

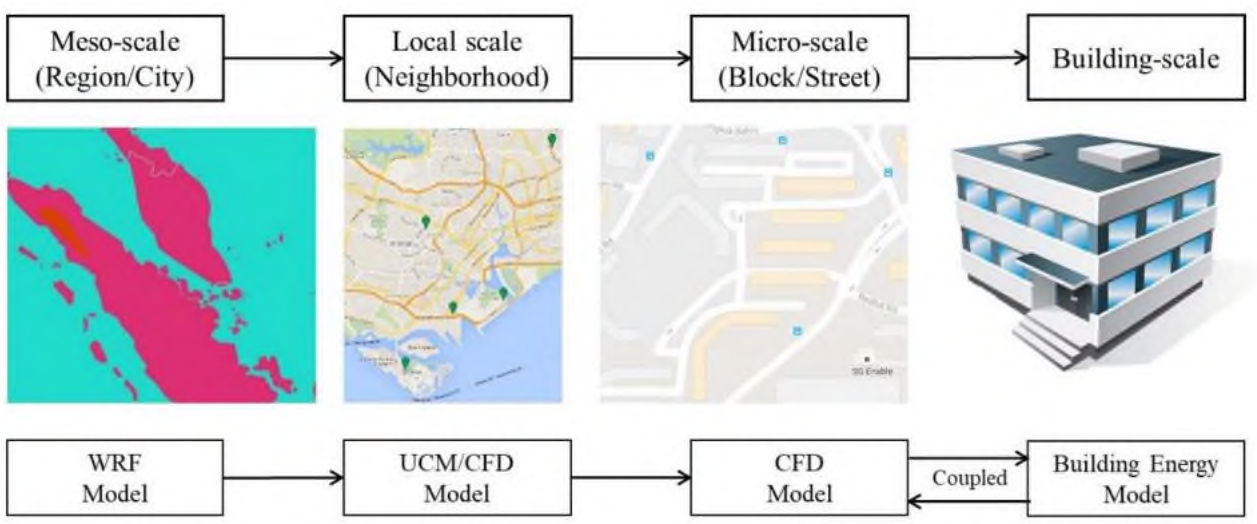

Fig. 1. Integration of the multiscale models for urban microclimate, Source: https://doi.org/10.1016/j.uclim.2020.100730

The model points to the need to strengthen the link between the building and the microclimate, quantifies the effectiveness of urban heat island (UHI) mitigation measures, assesses the impact of local climate on the energy demand of buildings and the impact of heat-generating air conditioning systems on the local climate. It is obvious that it is necessary 
to take into account the influence of urban heat islands when choosing structural solutions for buildings and choosing materials.

The main meso-scale climate-forming factors of the region are: solar radiation (light, heat, ultraviolet); atmospheric circulation (wind speed, direction, presence of atmospheric fronts); landscape features of the territory (flow of solar radiation, thermal conditions of the surface air layer, wind and air humidity conditions) (Fig. 2).

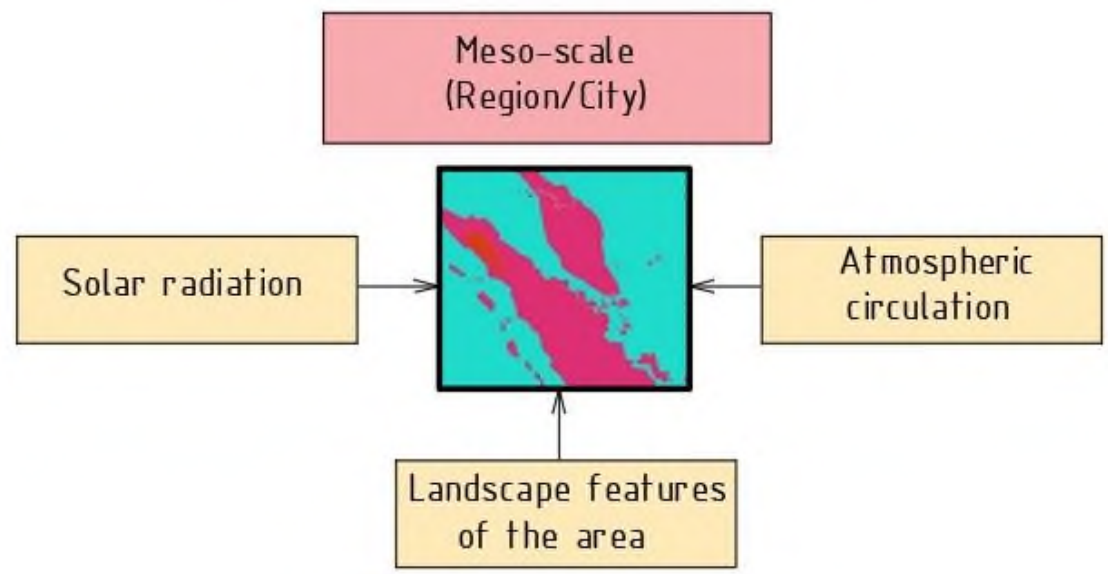

Fig. 2. Main meso-scale climate-forming factors of the region

Fig. 3 shows the local climate-forming factors of the city. These primarily include: direct heat emissions and changes in the solar radiation regime; dust and gas emissions from industrial enterprises and transport; changes in heat balance by reducing evaporation; rough terrain created by urban development.

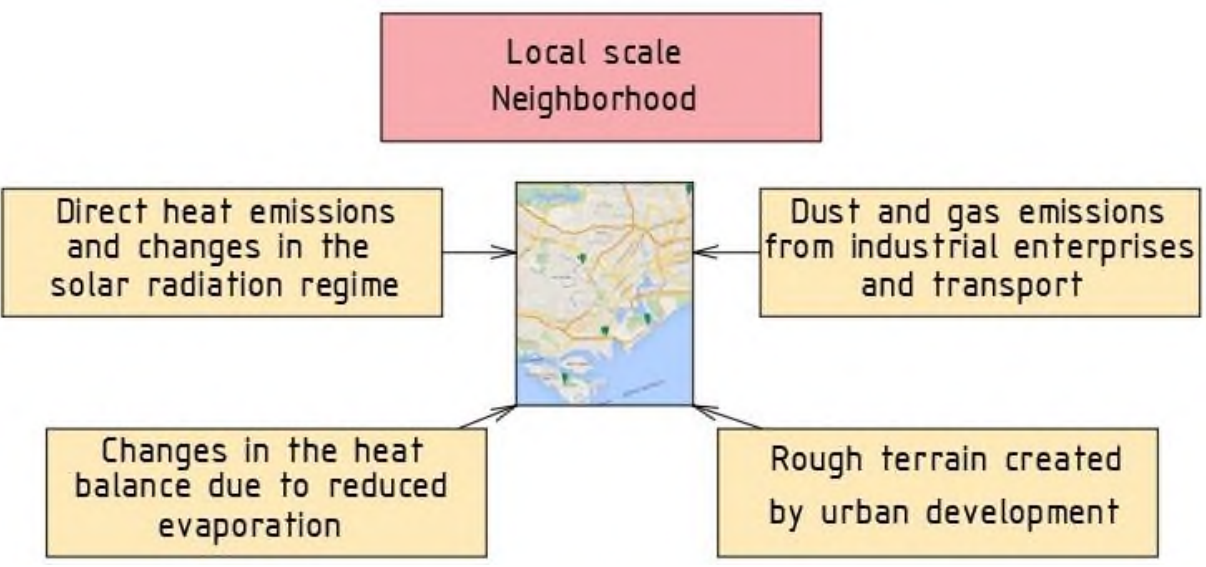

Fig. 3. Local climate-forming factors of the city

Fig. 4 shows the microclimate-forming factors of the block / street. These include urban development (density, the number of floors); heat capacity and reflectivity of elements of urban development (walls of buildings, roofs, roads, pavements); distribution of green spaces; natural and artificial reservoirs. 


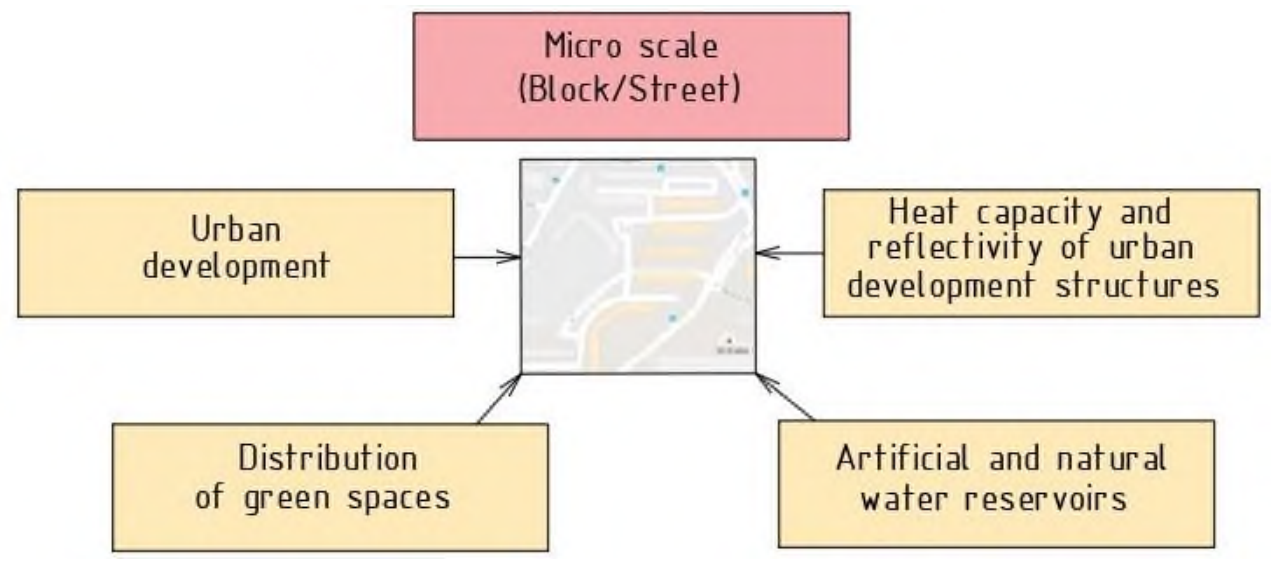

Fig. 4. Microclimate-forming factors of the block / street

In recent years, urban microclimate (UMC) research has made quite a lot of progress; however, it still finds little practical application. On the one hand, there is no methodology for a comprehensive analysis of all factors that form the microclimate of the city. On the other hand, practical implementation is hampered by the lack of clarity in target results that can be used by cities.

However, when it comes to other microclimatic parameters such as wind speed, relative humidity, albedo, solar insolation, urban canyon effect, street canyon effect, and their relationship or influence on each other are still very limitedly studied [6]. The work [7] also emphasizes that there are currently quite significant achievements in the methodologies for assessing the urban microclimate (UMC), but the implementation of the main conclusions for improving urban planning is not properly considered.

Urban Heat Islands (UHI) represent a major public health concern. One of the possible ways to mitigate them can be bodies of water. At the moment, the issues of the thermal effect of static water spaces on the urban microclimate are insufficiently studied. The analysis of the literature shows that there is a clear gap in knowledge regarding the physical interpretation of the contribution of water bodies to the urban microclimate [8].

\section{Results}

The problem of urban overheating is also proposed to solve by implementing the concept of a "zero-heating building" or a "neutral microclimate building", based on its energy efficiency, reducing carbon emissions and improving the quality of the indoor microclimate in premises [9].

The urban microclimate is also formed under the influence of aerodynamic flows, the redistribution of which is possible, including depending on the density of the building. City air permeability refers to the process of air exchange between flows above and within the urban canopy layers (UCL) and flow within the canopy. Greater building density provides a lower rate of air exchange, which reduces the city's ability to "breathe" [10].

The use of green spaces is of great importance for regulating the temperature regime in urban heat islands in a densely built environment. The results obtained indicate that the potential of trees to cool the ambient temperature and regulate the energy demand for cooling a building is mainly associated with radiation shading and a corresponding decrease in the increased solar heat of open facades of buildings. The reduced energy demand for cooling a building due to the addition of trees is directly related to their foliage density and planting patterns. Higher energy savings of up to $54 \%$ have been achieved with the trees forming a 
continuous shade canopy and with a leaf area density of $2.5 \mathrm{~m}^{2} / \mathrm{m}^{3}$. However, the cooling potential of the street trees was quite negligible when they were not tall enough to obscure most of the building's outer facade [11]. Green infrastructure needs to be established in a careful way. The selection of plants needs to consider local water availability and potential scarcity. The quantity of green spaces in the city is important for managing temperatures and other climate change impacts.

An increase in the urban forest cover is a frequently suggested strategy for mitigating the effects of urban heat waves, as trees are expected to cool cities through evapotranspiration and shade. However, trees also change the wind flow and urban aerodynamic situation, which could potentially limit heat dissipation. The existing studies show different cooling capacity of urban trees in different climates and at different times of the day [12].

All of the above factors affecting the urban microclimate must be taken into account when implementing the design and zoning principles to achieve the desired results. A number of modern studies are aimed at understanding how existing zoning rules affect the microclimate of densely built urban areas. The research shows that thermal mitigation strategies can be embedded both in the design phase and in the control system. By using more scientific approaches, designers and planners can optimize site design, including building shape, street geometry and landscape design standards, to reduce urban heat [13].

An adequate physical shape of city streets can contribute to the resilience of cities, in particular by improving urban microclimate. The safety and comfort of the urban environment is achieved by reducing energy consumption and associated greenhouse gas emissions, increasing social capital, improving the health and well-being of the population, and facilitating a quick and effective response to emergencies after natural disasters [14].

The impact of building density on the temperature of the earth's surface and its spatial features remain poorly understood. For example, the studies carried out for 21 cities in China show that the influence of building density on the surface temperature was more significant in areas with a dry climate compared to a humid climate. The influence of spatial dispersion and various urban planning determinants suggests that urban design and climate-sensitive planning should be based on standards developed for different climatic zones [15].

Buildings in cities consume up to $70 \%$ of all primary energy. In order to minimize the energy losses, it is necessary to reduce energy consumption and associated greenhouse gas emissions in buildings through energy conservation and efficiency gains [16]. Modern computational tools can simulate the design and operation of urban buildings from a city block to a district and an entire city, taking into account their interaction with each other and the urban environment around them. Energy modeling of urban buildings is a powerful tool for data-based planning and modernization of urban buildings, as well as the integration of buildings and networks.

Although there has been a lot of research done into natural factors including temperature, wind, and humidity and their impact on the environment factors influencing design and construction, still there is a need for field experiments with primary data collection and complex three-dimensional modeling and simulations. Today, the research community has a better understanding and appreciation of the factors having huge impact on the urban microclimate management. Fig. 5 presents the areas of research for further advancement of the UMC development. 


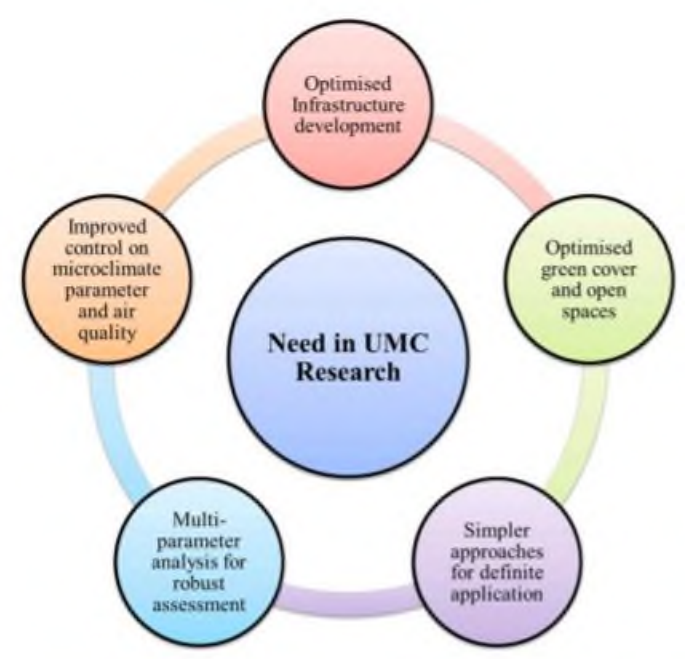

Fig. 5. Research need in UMC, Source: https://doi.org/10.1016/j.uclim.2020.100690

Currently, researchers can combine field studies with the satellite data to investigate the urban heat/dry island effect. This makes it possible to increase awareness of mutual influences of various meteorological and environmental factors. Yet, scientists rely primarily on the field data and verify their hypotheses, create more accurate models and bridge the data gap.

One of the challenges in urban microclimate research is to develop a framework for integrated assessment of the factors affecting the urban microclimate and to use wisely different tools to make the necessary changes and adjustments in the city's design and development. Along with the framework, it is also necessary to develop user-friendly approaches and methods, which can explain the required specific changes to optimize the city environment. The economic implications related to the optimization of the urban microclimate are the basis for the implementation success. It is expected the research community will use the key concepts discussed to develop strategies in the right direction.

\section{Conclusion}

1. The analysis of modern approaches to the problem of urban microclimate was carried out in order to generalize the main microclimate-forming factors in the urban environment.

2. The main microclimate-forming factors of the urban environment are not only the geographical features of cities, but also the density of buildings, the ecological situation, the thermal response of buildings, the influence of plants and water bodies.

3. The modern approach to modeling the urban microclimate is an integrated multilevel and systematic approach, since the problem of urban microclimate optimization is multifaceted and requires consideration of various factors at different levels.

4. Insufficient practical implementation of the already accumulated knowledge and research findings in design and construction, as well as the need to develop standards for the formation of the urban microclimate were noted.

\section{References}

1. H. Bherwani, A. Singh, R. Kumar, Urban Climate, 34, 100690 (2020) doi:10.1016/j.uclim.2020.100690 
2. N. Lauzet, A. Rodler, M. Musy, M-H. Azam, S. Guernouti, D. Mauree, T. Colinart, Renewable and Sustainable Energy Reviews, 116, $109390 \quad$ (2019) doi:10.1016/j.rser.2019.109390

3. M. Zinzi, S. Agnoli, C. Burattini, B. Mattoni, Solar Energy, 211, 1270-1282 (2020) doi:10.1016/j.solener.2020.10.050

4. M. Carpio, A. González, M. González, K. Verichev, Energy and Buildings, 226, 110379 (2020) doi.org/10.1016/j.enbuild.2020.110379

5. N. H. Wong, Y. He, N. S. Nguyen, S. V. Raghavan, M. Martin, D. J. C. Hii, J. Deng, Urban Climate, 35, 100730 (2021) doi:10.1016/j.uclim.2020.100730

6. H. Bherwani, A. Singh, R. Kumar, Urban Climate, 34, 100690 (2020) doi:10.1016/j.uclim.2020.100690

7. A. Boccalatte, M. Fossa, L. Gaillard, C. Menezo, Energy and Buildings, 110129 (2020) doi:10.1016/j.enbuild.2020.110129

8. P. Ampatzidis, T. Kershaw, Science of The Total Environment, 730, 139068 (2020) doi:10.1016/j.scitotenv.2020.139068

9. B.-J. He, Sustainable Cities and Society, 101647 (2019) doi:10.1016/j.scs.2019.101647

10. L. Chen, J. Hang, M. Sandberg, L. Claesson, Di S. Sabatino 2017 Procedia Engineering 198 758-769 doi:10.1016/j.proeng.2017.07.127

11. S. Tsoka, T. Leduc, A. Rodler, Sustainable Cities and Society, 65, 102633 (2020) doi.org/10.1016/j.scs.2020.102633

12. N. Meili, G. Manoli, P. Burlando, J. Carmeliet, T. L. W. Chowe, M. A. Coutts, M. Rith, E. Velasco, E. Vivini, S. Fatichi, Urban Forestry \& Urban Greening, 58, 26970 (2020) doi.org/10.1016/j.ufug.2020.126970

13. M. P. Heris, A. Middel, B. Muller, Landscape and Urban Planning, 202, 103870 (2020) doi:10.1016/j.landurbplan.2020.103870

14. A. Sharifi, Building and Environment (2018) doi:10.1016/j.buildenv.2018.09.040

15. J. Song, W. Chen, J. Zhang, K. Huang, B. Hou, A. V. Prishchepov, Landscape and Urban Planning, 198, 103794 (2020) doi:10.1016/j.landurbplan.2020.103794

16. T. Hong, Y. Chen, X. Luo, N. Luo, S. H. Lee, Building and Environment (2019) 106508 doi:10.1016/j.buildenv.2019.106508 